\title{
Optimasi Formula Tablet Floating Famotidin Menggunakan Kombinasi Matriks Gum Xanthan dan Hidroksi Propil Metil Selulosa K100M
}

\author{
Optimization of Famotidine Floating Tablet Formula with Combination of \\ Xanthan Gum and Hydroxy Propyl Methyl Cellulose K100M Matrixs
}

\author{
Shelinia Prima Sari, Angi Nadya Bestari*, T. N. Saifullah Sulaiman \\ Fakultas Farmasi, Universitas Gadjah Mada \\ Corresponding author: Angi Nadya Bestari: Email: angi@yahoo.com \\ Submitted: 21-6-2019 Revised:02-07-2019 Accepted:02-07-2019
}

\begin{abstract}
ABSTRAK
Famotidin adalah obat antihistamin $\mathrm{H}_{2}$ yang digunakan dalam pengobatan penyakit tukak lambung (peptic ulcer), tukak duodenal, ataupun keadaan hipersekresi yang patologis. Tablet floating famotidin dapat meningkatkan bioavailabilitas dengan mempertahankan waktu tinggal tablet dalam lambung dan mendekatkan famotidin pada tempat absorpsinya pada lambung bagian atas. Penelitian ini bertujuan untuk mengetahui komposisi optimum HPMC K100M serta gum xanthan dan pengaruh variasi keduanya terhadap sifat fisik granul dan tablet floating famotidin. Pembuatan delapan formula tablet floating famotidin menggunakan metode granulasi basah. Respon formula optimum didapat dengan evaluasi granul dan sifat fisik tablet. Evaluasi granul meliputi uji sifat alir dengan metode kecepatan alir dan uji daya serap granul. Evaluasi tablet meliputi keragaman bobot, kekerasan, kerapuhan, swelling index, floating lag time, total waktu floating, disolusi obat, dan penetapan kadar. Penentuan formula optimum menggunakan Design Expert versi 10.0.1. Peningkatan HPMC K100M meningkatkan daya serap granul, kekerasan tablet, dan swelling index secara signifikan. Peningkatan gum xanthan meningkatkan kecepatan alir granul, kerapuhan tablet, dan floating lag time secara signifikan. Kombinasi keduanya menurunkan persentase obat terdisolusi secara signifikan. Formula optimum tablet floating famotidin merupakan formula dengan kombinasi HPMC K100M sebesar 30\% b/b dan gum xanthan sebesar 5\% b/b.
\end{abstract}

Kata kunci: tablet floating, Famotidin, HPMC K100M, gum xanthan.

\begin{abstract}
Famotidine is an antihistamine $\mathrm{H}_{2}$ drug used in the treatment of peptic ulcers, duodenal ulcers, or pathological hypersecretion. Floating tablet famotidine can increase bioavailability by maintaining tablet residence time in the gastric and bringing famotidine closer to its absorption site in the upper part of gastric. This study aims to determine the optimum composition of HPMC K100M and xanthan gum and the effect of both variations on the physical properties of granules and floating tablets famotidine. Eight floating tablet formula famotidine made by wet granulation method. The optimum formula response was obtained by granule evaluation and physical properties of the tablet evaluation. Granule evaluation includes granules flow test by velocity method and granule absorption rate test. Tablet evaluation included weight diversity, hardness, friability, swelling index, floating lag time, total floating time, dissolution, and content determination. Determination of the optimum formula using Design Expert version 10.0.1. Increased HPMC K100M significantly increased the absorption rate of granules, tablet hardness, and swelling index. Increased xanthan gum significantly increased granule flow rate, tablet friability, and floating lag time. The combination of both significantly decreasing the percentage of drugs dissolved. The optimum formula for floating tablet famotidine is a formula with a combination of $30 \% \mathrm{w} / \mathrm{w}$ HPMC K100M and $5 \% \mathrm{w} / \mathrm{w}$ xanthan gum.
\end{abstract}

Keywords: tablet floating, famotidine, HPMC K100M, xanthan gum.

\section{PENDAHULUAN}

Famotidin merupakan obat antihistamin

H2 yang biasa digunakan untuk pengobatan penyakit tukak lambung (peptic ulcer), tukak duodenal, ataupun juga keadaan hipersekresi yang patologis misalnya pada sindrom Zollinger-Ellison. Famotidin memiliki bioavailabilitas yang rendah yaitu $40-45 \%$ dan 
memiliki shelf life 2,5-4 jam. Sebagai antagonis $\mathrm{H}_{2}$, famotidin memiliki daerah absorpsi spesifik pada sel parietal lambung yang berada di bagian atas lambung. Hal ini menjadikan famotidin merupakan salah satu obat yang cocok untuk dikembangkan menjadi sediaan dengan kemampuan retensi lambung dengan mekanisme floating gastroretentive yang diharapkan dapat meningkatkan bioavailabilitas dari famotidin. Floating gastroretentive dapat menghantarkan obat dengan tepat kepada site of action, menyediakan obat dalam rentang terapetik selama periode yang lebih lama, mengurangi frekuensi pemakaian, meminimalisir fluktuasi kadar obat dalam plasma, dan tentunya meningkatkan bioavailabilitas.

HPMC merupakan polimer sintetis turunan selulosa yang dapat digunakan sebagai matriks sediaan lepas lambat dengan mekanisme membentuk lapisan hidrogel dengan viskositas tinggi pada sekeliling sediaan setelah kontak dengan saluran pencernaan. Lapisan hidrogel ini mampu menghalangi lepasnya obat dari sediaan sehingga kecepatan pelepasan obat dapat dikendalikan (Suwaldi dan Faizah, 1994). Gum xanthan merupakan polimer alam yang dapat juga digunakan sebagai matriks tablet. Gum xanthan sangat potensial digunakan sebagai bahan pembawa obat karena bersifat free flowing, inert dan biocompatible.

Kedua polimer ini merupakan polimer hidrofilik yang bekerja dengan mekanisme masuknya hidrasi cairan gastrointestinal yang menyebabkan perenggangan rantai sehingga matriks akan mengembang dan membentuk lapisan gel. Lapisan gel ini terbentuk dengan adanya crosslinking dan dapat mengontrol proses difusi cairan ke dalam sistem maupun proses difusi obat keluar dari sistem sampai pada waktu tertentu. Tentunya dengan mengontrol proses difusi diharapkan dapat memberikan hasil output yang lebih menguntungkan dibandingkan dengan sediaan tablet konvensional misalnya pada parameter disolusi obat. Penelitian ini dilakukan bertujuan untuk mengetahui pengaruh kombinasi kedua polimer terhadap sifat fisik floating tablet famotidin serta memperoleh perbandingan optimum kedua polimer tersebut.

\section{METODOLOGI \\ Alat}

Alat yang digunakan adalah neraca analitik (Ohaus ${ }^{\circledR}$, Cina), Cube mixer Erweka ${ }^{\circledR}$ (Jerman), alat uji sifat alir Granulate-tester (tipe GT atau GTB), seperangkat alat uji daya serap air, Fluid Bed Dryer, mesin tablet single punch (Korch EK-1, Jerman), Tablet Hardness Tester (Vaguard YD-2), alat uji disolusi (tipe DT 600), Tablet-Abrasion dan Friability Tester (Erweka TA-20), spektrofotometer UV-Vis Genesys, stopwatch digital, mortir, stamper, ayakan no. 16 dan no. 18 mesh (Indotest Multi Laboratama), vacuum cleaner, cawan petri, pipet volume, mikropipet, tabung reaksi, dan beaker glass.

\section{Bahan}

Bahan yang digunakan dalam pembuatan tablet floating ini adalah famotidin kualitas farmasetis dari PT. Sanbe Farma, HPMC K100M (kualitas farmasetis, PT. Kalbe Farma), gum xanthan (kualitas farmasetis, Bratachem), asam sitrat (kualitas farmasetis, Bratachem), natrium bikarbonat (kualitas farmasetis, Bratachem), amilum (kualitas farmasetis, Bratachem), Avicel ${ }^{\circledR} \quad$ PH 102 (kualitas farmasetis, Bratachem), dan magnesium stearat (kualitas farmasetis, Bratachem). Pada uji sifat fisik tablet bahan yang digunakan adalah akuades dan $\mathrm{HCl}$ $37 \%$.

\section{Jalannya Penelitian \\ Pembuatan kurva baku famotidin}

Pembuatan kurva baku diawali dengan scanning panjang gelombang maksimum famotidin dengan cara membuat larutan berkonsentrasi $10 \mu \mathrm{g} / \mathrm{mL}$ kemudian dilakukan scanning dengan spektrofotometer UV-Vis pada panjang gelombang 200-400 nm.

Kemudian dibuat larutan famotidin dengan konsetrasi $5,10,15,20,25$, dan $30 \mu \mathrm{g} / \mathrm{mL}$. Diukur absorbansinya pada panjang gelombang maksimum yang telah diperoleh dan hasil absorbansi yang diperoleh digunakan untuk membuat kurva regresi linier.

\section{Verifikasi metode analisis}

Verifikasi metode analisis dilakukan melalui perhitungan presisi dan akurasi yang didapatkan dengan mengukur absorbansi larutan sampel dengan konsentrasi 5, 10, dan 
Tabel I. Formula Tablet Floating Famotidin dengan Kombinasi Polimer HPMC K100M dan Gum Xanthan

\begin{tabular}{|c|c|c|c|c|c|c|c|c|}
\hline \multirow[b]{2}{*}{ Bahan } & \multicolumn{8}{|c|}{ Bobot (mg) } \\
\hline & Run I & Run II & Run III & Run IV & Run $V$ & Run VI & Run VII & $\begin{array}{l}\text { Run } \\
\text { VIII }\end{array}$ \\
\hline Famotidin & 40 & 40 & 40 & 40 & 40 & 40 & 40 & 40 \\
\hline HPMC K100M & 68,75 & 50 & 62,5 & 75 & 56,25 & 75 & 50 & 62,5 \\
\hline Gum xanthan & 18,75 & 37,5 & 25 & 12,5 & 31,25 & 12,5 & 37,5 & 25 \\
\hline Asam sitrat & 16,2 & 16,2 & 16,2 & 16,2 & 16,2 & 16,2 & 16,2 & 16,2 \\
\hline $\begin{array}{l}\text { Natrium } \\
\text { bikarbonat }\end{array}$ & 21,3 & 21,3 & 21,3 & 21,3 & 21,3 & 21,3 & 21,3 & 21,3 \\
\hline Avicel PH102 ${ }^{\circledR}$ & 72,5 & 72,5 & 72,5 & 72,5 & 72,5 & 72,5 & 72,5 & 72,5 \\
\hline Amilum & 7.5 & 7.5 & 7.5 & 7.5 & 7.5 & 7.5 & 7.5 & 7.5 \\
\hline Mg stearat & 5 & 5 & 5 & 5 & 5 & 5 & 5 & 5 \\
\hline Bobot total & 250 & 250 & 250 & 250 & 250 & 250 & 250 & 250 \\
\hline
\end{tabular}

$15 \mu \mathrm{g} / \mathrm{mL}$ pada panjang gelombang maksimum famotidin. Selain itu juga menggunakan perhitungan LoQ dan LoD yang dihitung dengan mengukur absorbasi pelarut yang digunakan yaitu $\mathrm{HCl} 0,1 \mathrm{~N}$ dengan blangko akuades pada panjang gelombang maksimum famotidin.

Penyiapan formula tablet floating famotidin Formula floating tablet famotidin diperoleh melalui software Design Expert ${ }^{\circledR} 10$ dengan metode Mixture Simplex Lattice Design. Formula tablet floating famotidin dengan variasi komposisi polimer yaitu HPMC dan gum xanthan dengan jumlah keduanya selalu sama yaitu 87,5 mg tiap tablet dengan rentang kadar gum xanthan 12,5-37,5 mg dan HPMC K100M 50-75 mg. Tiap tablet mengandung zat aktif yaitu famotidin sebesar $40 \mathrm{mg}$ dengan bobot total tablet $250 \mathrm{mg}$. Sesuai SLD, terdapat lima formula variasi komposisi HPMC dan gum xanthan ditambah replikasi pada rentang atas, bawah, dan tengah sehingga ada total keseluruhan 8 run. Formula tablet floating famotidin (Tabel I).

\section{Pembuatan tablet floating famotidin}

Tablet floating famotidin dibuat dengan metode granulasi basah. Famotidin, HPMC, gum xanthan, natrium bikarbonat dan setengah bagian Avicel $\mathrm{PH}_{102}{ }^{\circledR}$ dicampurkan menggunakan cube mixer dengan kecepatan 20 rpm selama 10 menit, lalu serbuk digranulasi dengan bahan pengikat musilago amili $10 \%$, lalu diayak basah dengan ayakan no. 16 mesh, lalu granul dikeringkan menggunakan fluid bed dryer selama 10 menit dengan suhu $40^{\circ} \mathrm{C}$ selama dua kali proses, lalu granul kering diayak dengan ayakan no. 18 mesh, lalu dilanjutkan pencampuran kedua dengan asam sitrat, mg stearat, dan Avicel PH102 ${ }^{\circledR}$ menggunakan cube mixer selama 5 menit dengan kecepatan yang sama, lalu granul dikempa dengan menggunakan mesin kempa tablet.

\section{Pengujian kecepatan alir dan daya serap granul \\ Kecepatan alir granul \\ Kecepatan alir granul dihitung dengan cara menghitung waktu yang diperlukan oleh granul untuk mengalir melewati corong. Granul sebanyak 50 gram ditimbang, kemudian dituang ke dalam corong. Penutup yang berada di dasar corong dibuka dan dihitung waktu yang diperlukan oleh granul untuk turun seluruhnya dari dalam corong (Mariyana dkk., 2012)}

\section{Daya serap granul}

Uji daya serap granul dilakukan dengan serangkaian alat uji daya serap. Granul sebanyak $100 \mathrm{mg}$ ditempatkan di atas kertas saring yang sudah terjenuhi air. Berkurangnya bobot air yang ditimbang di atas neraca analitik sebanding dengan banyaknya air yang diserap granul. Uji ini dilakukan sampai terjadi pengurangan bobot air yang konstan atau sekitar 15 menit (Swarbrick, 1992).

\section{Pengujian sifat fisik tablet}

Keragaman bobot

Ditimbang seksama 10 tablet satu persatu, lalu dihitung jumlah zat aktif dalam tiap tablet yang dinyatakan dalam persen dari 
jumlah yang tertera dalam etiket dari hasil penetapan kadar masing-masing tablet. Dihitung Nilai Penerimaan (NP) (Departemen Kesehatan, 2014)

\section{Kekerasan}

Diambil 10 tablet pada masing-masing run kemudian diukur kekerasannya dengan menggunakan hardness tester.

Kerapuhan

Dibebasdebukan 10 tablet dan ditimbang untuk mengetahui bobot awal. Tablet dimasukkan ke dalam alat uji kerapuhan (friability tester) dengan rotasi $25 \mathrm{rpm}$ selama 4 menit. Tablet dibebasdebukan kembali dan ditimbang kembali sebagai bobot akhir tablet.

\section{Swelling index}

Diletakkan tablet pada cawan petri yang telah diisi dengan medium $\mathrm{HCl} 0,1 \mathrm{~N}$ pada temperatur kamar. Bobot tablet awal dihitung terlebih dahulu. Tablet yang sudah menyerap air diukur bobotnya selama interval waktu menit ke-5, 10, 15, 30, 45, 60, 90, 120, 150, 180, 210, 270, 300, dan 360 (Ajay Kumar dkk., 2013).

\section{Floating lag time dan total floating time}

Tablet diletakkan di dalam beaker glass $100 \mathrm{~mL}$ yang mengandung simulasi cairan lambung, $\mathrm{pH} 1,2(\mathrm{HCl} 0,1 \mathrm{~N})$ dengan suhu $37^{\circ} \mathrm{C}$. Waktu yang diperlukan tablet untuk naik ke permukaan dan mengapung dicatat sebagai floating lag time (FLT). Durasi tablet untuk tetap konstan di permukaan media dicatat sebagai total floating time (Bomma dkk., 2009)

Penetapan kadar

Ditimbang dan diserbukkan tidak kurang 20 tablet, lalu ditimbang seksama serbuk tablet setara lebih kurang $25 \mathrm{mg}$ Famotidin. Serbuk dimasukkan ke dalam labu ukur 50,0 ml, ditambahkan $10 \mathrm{ml} \mathrm{HCl} 0,1 \mathrm{~N}$, dikocok dan diencerkan dengan $\mathrm{HCl}$ 0,1N sampai garis tanda, lalu disaring. $5 \mathrm{ml}$ filtrat pertama dibuang. Dipipet 10,0 ml filtrat, dimasukkan ke dalam tabu ukur 50,0 ml, diencerkan dengan $\mathrm{HCl}$ 0,1N sampai garis tanda. Dipipet 3,5 larutan, dimasukkan ke dalam labu ukur 25,0 ml, diencerkan dengan $\mathrm{HCl} 0,1 \mathrm{~N}$ sampai garis tanda. Kemudian diukur serapan pada panjang gelombang maksimum dengan $\mathrm{HCl} 0,1 \mathrm{~N}$ sebagai blanko.
Uji disolusi

Dilakukan menggunakan alat uji disolusi aparatus 1 (tipe keranjang) dengan menggunakan media $900 \mathrm{ml} \mathrm{HCl} \mathrm{0,1} \mathrm{N}$, pada suhu $37 \pm 0,5^{\circ} \mathrm{C}$ dengan kecepatan $50 \mathrm{rpm}$. Pengambilan sampel $(5,0 \mathrm{ml})$ dilakukan pada menit ke-15, 30, 45, 60, 90, 120, 150, 180, 240, $300,360,420,480$. Jumlah cairan yang terambil diganti oleh sejumlah yang sama larutan $\mathrm{HCl}$ 0,1 N. Sampel kemudian diukur serapannya dengan spektrofotometer UV pada panjang gelombang $265 \mathrm{~nm}$. Profil pelepasan obat ditentukan dengan memplot persentase obat yang dilepaskan terhadap waktu (Sagita dkk, 2011).

\section{Penentuan formula optimum}

Data yang diperoleh kemudian diolah menggunakan metode Simplex Lattice Design (SLD). Data respon kedelapan run dimasukkan ke dalam desain, kemudian diperoleh grafik dari masing-masing sifat fisik. Formula optimum dapat diperoleh dengan menentukan terlebih dahulu kriteria maupun tingkat kepentingan dari setiap respon yang dikehendaki. Solusi akan ditampilkan sebagai bentuk grafik. Grafik dari Numerical Optimization akan menunjukkan point prediction dari formula optimum terpilih dengan nilai desirability tertinggi.

\section{Pembuatan formula optimum}

Formula optimum tablet floating famotidin yang telah terpilih kemudian dibuat dengan cara yang sama seperti sebelumnya. Formula optimum dievaluasi sifat granul dan tabletnya sama seperti sebelumnya.

\section{Evaluasi formula optimum}

Evaluasi formula optimum dilakukan dengan membandingkan nilai respon sifat fisik serbuk dan tablet antara hasil prediksi SLD dengan tablet optimum yang dibuat. Metode analisis yang digunakan adalah one sample $T$ test.

\section{HASIL DAN PEMBAHASAN \\ Kurva Baku Famotidin}

Pembuatan kurva baku famotidin dilakukan dengan scanning panjang gelombang maksimum dengan spektrofotometer UV pada rentang 200-400 nm. Grafik kurva baku famotidin ditunjukkan melalui (Gambar 1) dan hasil kurva baku famotidin ditunjukkan pada persamaan 1 dengan nilai koefisien korelasi (r) 


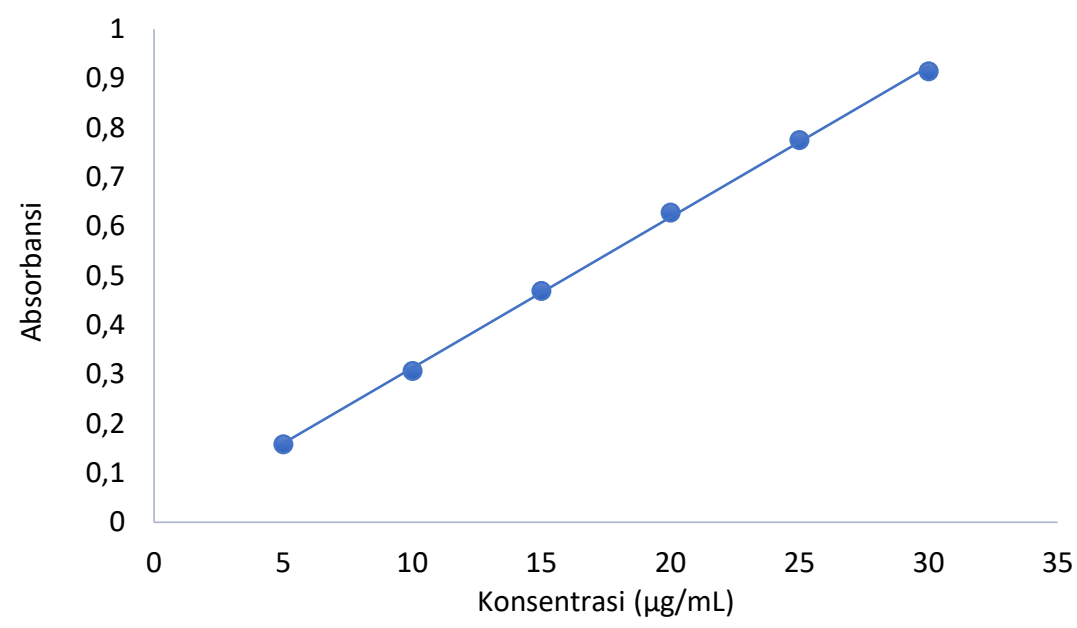

Gambar 1. Kurva Baku Famotidin

Tabel II. Nilai Recovery (\%) dan Koefisien Variasi (\% CV) Pengukuran Famotidin dengan Spektrofotometer UV-Vis

\begin{tabular}{cccc}
\hline Kadar sampel $(\boldsymbol{\mu g} / \mathbf{m l})$ & Kadar Terukur $(\boldsymbol{\mu g} / \mathbf{m l})$ & Recovery (\%) & CV (\%) \\
\hline $5,00 \pm 0,00$ & $5,09 \pm 0,14$ & $101,83 \pm 2,83$ & 2,78 \\
$20,00 \pm 0,01$ & $20,49 \pm 0,39$ & $102,46 \pm 1,91$ & 1,87 \\
$30,00 \pm 0,01$ & $30,57 \pm 0,81$ & $101,89 \pm 2,68$ & 2,63 \\
\hline
\end{tabular}

yang diperoleh adalah 0,997

$$
y=0,03 x+0,01 Y=0,0306 x+0,0072
$$

\section{Verifikasi Metode Analisis}

Akurasi

Akurasi merupakan kesesuaian hasil analisis dengan nilai yang diterima sebagai nilai benar (acceptance value). Akurasi dinyatakan dalam persen recovery atau perolehan kembali. Metode dinyatakan akurat apabila nilai rata-rata perolehan kembali berada pada rentang 80 $110 \%$ untuk konsentrasi $10 \mu \mathrm{g} / \mathrm{mL}$ dan 90 107\% untuk konsentrasi $100 \mu \mathrm{g} / \mathrm{mL}$ (AOAC, 2012). Tabel II menampilkan hasil nilai perolehan kembali (recovery) dari masingmasing level konsentrasi yang berkisar antara $101,83 \%$ - 102,46\% sehingga akurasi metode memenuhi persyaratan yang ditetapkan AOAC.

Presisi

Presisi merupakan parameter yang menunjukkan bahwa metode tersebut menghasilkan suatu hasil analisis yang sama atau hampir sama dalam satu seri pengukuran atau penetapan. Presisi dihitung dengan melihat koefisien variasi (CV) dari masing-masing konsentrasi. Metode dinyatakan memiliki presisi baik apabila nilai CV tidak lebih besar dari 7,3\% untuk konsentrasi $10 \mu \mathrm{g} / \mathrm{mL}$, dan tidak lebih besar dari 5,3\% untuk konsentrasi $100 \mu \mathrm{g} / \mathrm{mL}$ (AOAC, 2012). Hasil pada (Tabel II) menunjukkan bahwa tidak ada nilai presisi yang lebih besar daripada 7,3\% sehingga dapat dinyatakan bahwa metode memiliki presisi yang baik atau motode dapat menghasilkan analisa yang sama atau hampir sama dalam satu seri pengukuran atau penetapan.

\section{LOD dan LOQ}

Limit of Detection (LoD) merupakan konsentrasi analit terendah dalam sampel yang masih dapat dideteksi namun tidak diperlukan secara kuantitatif. Limit of Quantification (LoQ) merupakan konsentrasi terendah analit yang masih dapat terkuantifikasi secara tepat dan teliti. Nilai LoD dan LoQ dihitung berdasarkan kurva baku famotidin dalam $\mathrm{HCl} 0,1 \mathrm{~N}$. Berdasarkan perhitungan, konsentrasi terendah analit yang masih dideteksi namun tidak 
Optimasi Formula Tablet Floating Famotidin Menggunakan Kombinasi Matriks Gum Xanthan

Tabel III. Nilai Limit of Detection dan Limit of Quantification

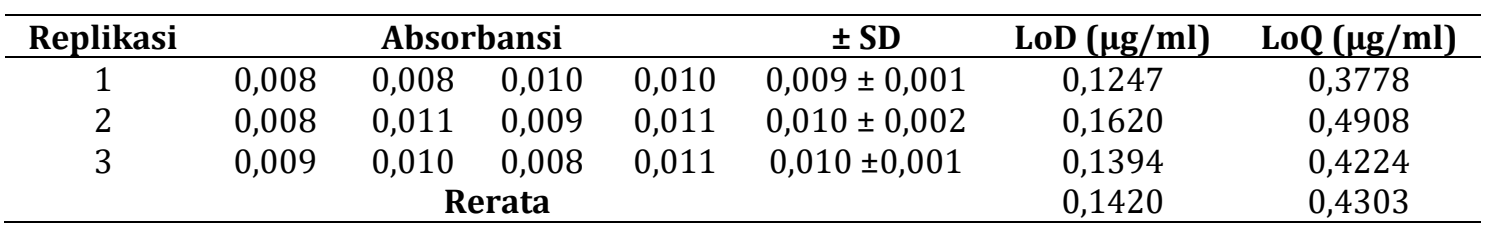

Tabel IV. Hasil Uji Sifat Alir dan Daya Serap Granul Tablet Floating Famotidin

\begin{tabular}{ccc}
\hline Run & Kecepatan Alir (g/detik) & Daya Serap $(\boldsymbol{\mu g} / \mathbf{m e n i t})$ \\
\hline 1 & $25,46 \pm 0,69$ & $8,49 \pm 0,97$ \\
2 & $29,54 \pm 1,25$ & $8,49 \pm 0,97$ \\
3 & $27,82 \pm 1,24$ & $8,33 \pm 0,67$ \\
4 & $26,44 \pm 0,76$ & $8,42 \pm 0,47$ \\
5 & $32,17 \pm 0,82$ & $9,25 \pm 0,92$ \\
6 & $23,94 \pm 0,65$ & $7,27 \pm 0,90$ \\
7 & $31,80 \pm 1,56$ & $6,43 \pm 0,61$ \\
8 & $31,66 \pm 0,79$ & $6,85 \pm 0,97$ \\
\hline
\end{tabular}

Keterangan: R1 : 68,75 mg HPMC K100M + 18,75 mg Gum xanthan; R2 : 50 mg HPMC K100M + 37,5 mg Gum xanthan; R3 : 62,5 mg HPMC K100M + 25 mg Gum xanthan; R4 : 75 mg HPMC K100M + 12,5 mg Gum xanthan; R5 : 56,25mg HPMC K100M + 31,25 mg Gum xanthan; R6 : 75 mg HPMC K100M +12,5 mg Gum xanthan; R7 : 50 mg HPMC K100M + 37,5 mg Gum xanthan; R8 : 62,5 mg HPMC K100M $+25 \mathrm{mg}$ Gum xanthan

diperlukan secara kuantitatif (LoD) adalah sebesar 0,1420 $\mu \mathrm{g} / \mathrm{ml}$ dan konsentrasi terendah analit yang masih dapat terkuantifikasi (LoQ) adalah sebesar $0,4303 \mu \mathrm{g} / \mathrm{ml}$. Tabel III menunjukkan hasil Limit of Detection (LoD) dan Limit of Quantification (LoQ).

\section{Sifat Alir dan Daya Serap Granul}

Sifat alir granul

Sifat alir granul digambarkan dengan kecepatan alir dari serbuk. Semakin besar kecepatan alirnya maka akan semakin baik sifat alirnya. Hasil evaluasi kecepatan alir (Tabel IV).

Hasil menunjukkan semakin sedikit persentase HPMC K100M dan semakin besar persentase gum xanthan maka serbuk akan memiliki kecepatan alir yang lebih besar. Hal ini disebabkan karena gum xanthan dapat menghasilkan granul dengan berat jenis yang lebih besar dibandingkan dengan berat jenis dari granul HPMC sehingga granul menjadi lebih mudah mengalir (Siswanto dan Sulihtyowati, 2006). HPMC memiliki sifat higroskopis sehingga granul yang dihasilkan akan memiliki gaya tarik menarik yang kuat dan menyebabkan granul tidak menyebar dengan baik (Cahyo, 2012).
Daya serap granul

Daya serap ini berkaitan dengan higroskopisitas granul atau kemampuan granul untuk menyerap air. Hasil uji daya serap (Tabel IV) menunjukkan nilai yang cukup tinggi sehingga daya serap granul sudah cukup baik. Hasil menunjukkan bahwa semakin tinggi persentase HPMC K100M dan semakin rendah persentase gum xanthan dapat meningkatkan daya serap granul. Namun kombinasi keduanya menghasilkan interaksi saling sinergis dalam meningkatkan daya serap granul. Hal ini disebabkan karena HPMC K100M dan gum xanthan merupakan polimer hidrofilik yang memiliki kemampuan kuat menarik air kemudian pengunaan kedua matriks ini dapat membentuk lapisan gel ketika kontak dengan medium sehingga proses penyerapan meningkat.

\section{Sifat Fisik Tablet Floating Famotidin}

Keragaman bobot

Uji keragaman bobot ini berkaitan dengan homogenitas dari bahan aktif maupun eksipien di dalam tablet. Keragaman bobot tablet dinyatakan dengan Nilai Penerimaan (NP). Tablet dinyatakan seragam apabila memiliki 
Tabel V. Hasil Uji Sifat Fisik Tablet Floating Famotidin dengan Kombinasi HPMC K100M dan Gum Xanthan

\begin{tabular}{|c|c|c|c|c|c|c|c|c|c|}
\hline \multicolumn{2}{|c|}{ Run } & 1 & 2 & 3 & 4 & 5 & 6 & 7 & 8 \\
\hline \multicolumn{2}{|c|}{ NP (\%) } & 2,08 & 2,66 & 2,75 & 1,25 & 1,97 & 2,09 & 2,45 & 1,86 \\
\hline \multicolumn{2}{|c|}{$\begin{array}{l}\text { Kekerasan } \\
\text { (kg) }\end{array}$} & $\begin{array}{c}9,40 \pm \\
0,30\end{array}$ & $\begin{array}{c}8,20 \pm \\
0,11\end{array}$ & $\begin{array}{c}8,20 \pm \\
0,13\end{array}$ & $\begin{array}{c}10,30 \pm \\
0,21\end{array}$ & $\begin{array}{c}8,69 \pm \\
0,19\end{array}$ & $\begin{array}{c}9,99 \pm \\
0,34\end{array}$ & $\begin{array}{c}9,56 \pm \\
0,13\end{array}$ & $\begin{array}{c}7,59 \pm \\
0,09\end{array}$ \\
\hline \multicolumn{2}{|c|}{$\begin{array}{c}\text { Kerapuhan } \\
\text { (\%) }\end{array}$} & $\begin{array}{c}0,46 \pm \\
0,02\end{array}$ & $\begin{array}{c}0,56 \pm \\
0,02\end{array}$ & $\begin{array}{c}0,47 \pm \\
0,02\end{array}$ & $\begin{array}{c}0,35 \pm \\
0,01\end{array}$ & $\begin{array}{c}0,51 \pm \\
0,01\end{array}$ & $\begin{array}{l}0,35 \pm \\
0,01\end{array}$ & $\begin{array}{c}0,62 \pm \\
0,03\end{array}$ & $\begin{array}{c}0,42 \pm \\
0,01\end{array}$ \\
\hline \multicolumn{2}{|c|}{$\begin{array}{c}\text { Swelling index } \\
\text { (\%) }\end{array}$} & $\begin{array}{r}259,82 \\
+1296\end{array}$ & $\begin{array}{c}239,83 \pm \\
889\end{array}$ & $\begin{array}{r}241,54 \\
+519\end{array}$ & 271,36 & 239,45 & 263,00 & 238,23 & 254,87 \\
\hline \multicolumn{2}{|c|}{$\begin{array}{l}\text { Floating lag } \\
\text { time (detik) }\end{array}$} & $\begin{array}{c}68,75 \pm \\
1,71\end{array}$ & $\begin{array}{c}131,50 \pm \\
5,80\end{array}$ & $\begin{array}{l}110,50 \\
\pm 4,65\end{array}$ & $\begin{array}{c}58,25 \pm \\
1,71\end{array}$ & $\begin{array}{l}118,25 \\
\pm 4,57\end{array}$ & $\begin{array}{r}39,75 \pm \\
1,71\end{array}$ & $\begin{array}{l}126,50 \\
\pm 4,20\end{array}$ & $\begin{array}{l}-07,75 \\
\pm 4,11\end{array}$ \\
\hline \multicolumn{2}{|c|}{$\begin{array}{c}\text { Total floating } \\
\text { time (jam) }\end{array}$} & 24 & 24 & 24 & 24 & 24 & 24 & 24 & 24 \\
\hline \multicolumn{2}{|c|}{$\begin{array}{c}\text { Penetapan } \\
\text { kadar }\end{array}$} & $\begin{array}{c}94,08 \pm \\
2,50\end{array}$ & $\begin{array}{c}94,33 \pm \\
0,94\end{array}$ & $\begin{array}{r}95,25 \\
\pm 3,53\end{array}$ & $\begin{array}{c}91,72 \pm \\
1,29\end{array}$ & $\begin{array}{r}92,58 \\
\pm 2,08\end{array}$ & $\begin{array}{r}92,15 \pm \\
4,66\end{array}$ & $\begin{array}{r}98,38 \\
\pm 2,09\end{array}$ & $\begin{array}{c}95,47 \pm \\
0,70\end{array}$ \\
\hline \multirow{3}{*}{ Disolusi } & $\begin{array}{l}\mathbf{L}_{120} \\
(\%)\end{array}$ & $\begin{array}{c}35,57 \pm \\
1,51\end{array}$ & $\begin{array}{c}37,99 \pm \\
3,22\end{array}$ & $\begin{array}{r}35,59 \\
\pm 0,63\end{array}$ & $\begin{array}{c}32,98 \pm \\
0,82\end{array}$ & $\begin{array}{r}35,25 \\
\pm 2,15\end{array}$ & $\begin{array}{r}32,85 \pm \\
1,36\end{array}$ & $\begin{array}{r}37,32 \\
\pm 2,75\end{array}$ & $\begin{array}{r}34,47 \pm \\
0,63\end{array}$ \\
\hline & $\begin{array}{l}\text { L240 } \\
\text { (\%) }\end{array}$ & $\begin{array}{c}50,87 \pm \\
5,77\end{array}$ & $\begin{array}{c}60,99 \pm \\
2,60\end{array}$ & $\begin{array}{r}50,73 \\
\pm 5,73\end{array}$ & $\begin{array}{c}45,77 \pm \\
0,75\end{array}$ & $\begin{array}{l}47,13 \\
\pm 0,55\end{array}$ & $\begin{array}{c}52,27 \pm \\
1,68\end{array}$ & $\begin{array}{l}52,66 \\
\pm 2,08\end{array}$ & $\begin{array}{r}45,75 \pm \\
1,32\end{array}$ \\
\hline & $\begin{array}{l}\text { L480 } \\
(\%)\end{array}$ & $\begin{array}{c}71,51 \pm \\
0,20\end{array}$ & $\begin{array}{c}80,89 \pm \\
0,73\end{array}$ & $\begin{array}{r}74,38 \\
\pm 2,66\end{array}$ & $\begin{array}{c}72,53 \pm \\
2,21\end{array}$ & $\begin{array}{r}72,30 \\
\pm 1,01\end{array}$ & $\begin{array}{c}77,20 \pm \\
4,81\end{array}$ & $\begin{array}{r}75,68 \\
\pm 5,12 \\
\end{array}$ & $\begin{array}{c}64,14 \pm \\
2,74\end{array}$ \\
\hline
\end{tabular}

Keterangan: Run $1: 68,75$ mg HPMC K100M + 18,75 mg gum xanthan; Run $2: 50$ mg HPMC K100M + 37,5 mg gum xanthan; Run $3: 62,5$ mg HPMC K100M + 25 mg gum xanthan; Run $4: 75$ mg HPMC K100M + 12,5 mg gum xanthan; Run $5: 56,25 \mathrm{mg}$ HPMC K100M + 31,25 mg gum xanthan; Run $6: 75$ mg HPMC K100M +12,5 mg gum xanthan; Run $7: 50$ mg HPMC K100M + 37,5 mg gum xanthan; Run $8: 62,5 \mathrm{mg}$ HPMC K100M + 25 mg gum xanthan

$\mathrm{NP} \leq 15 \%$. Nilai penerimaan dari masing-masing run (Tabel V) berada di bawah $15 \%$ sehingga dapat dinyatakan bahwa tablet yang dihasilkan seluruhnya memenuhi persyaratan keragaman bobot.

Kekerasan

Hasil evaluasi kekerasan (Tabel V). Hasil menunjukkan penambahan persentase HPMC K100M dan gum xanthan dapat meningkatkan kekerasan tablet. Gum xanthan dapat menghasilkan granul dengan ukuran yang lebih besar sehingga dapat meningkatkan kompaktibilitas tablet. Gum xanthan juga memiliki daya rekat yang sangat tinggi sehingga dapat meningkatkan kekerasan tablet (Iskandarsyah dkk., 2010). Gum xanthan berpengaruh dalam meningkatkan kompaktibilitas tablet (Siswanto dan Sulihtyowati, 2006) sehingga semakin tinggi konsentrasinya maka akan semakin kompak tablet yang dihasilkan.
Kerapuhan

Kerapuhan tablet menggambarkan ketahanan tablet dalam melawan berbagai gangguan dari lingkungan seperti gesekan dan pengikisan. Hasil evaluasi kerapuhan (Tabel V). Kerapuhan tablet menurun seiring dengan bertambahnya persentase HPMC. Hal ini bisa disebabkan gum xanthan memiliki karakteristik mudah menyerap uap air pada permukaan tablet sehingga menyebabkan bagian permukaan tablet menjadi kurang kompak atau rapuh (Hadisoewignyo dan Fudholi, 2007).

Swelling Index

Swelling index dilakukan untuk melihat kemampuan mengembang dari tablet sehingga dapat berpengaruh kepada proses mengapungnya sediaan. Semakin besar swelling index maka akan semakin besar tablet mengembang. Hasil evaluasi swelling index (Tabel V). Hasil menunjukkan semakin besar persentase dari HPMC K100M dan semakin kecil persentase dari gum xanthan 
akan meningkatkan swelling index tablet. Hal ini disebabkan karena kombinasi keduanya menghasilkan interaksi saling sinergis dalam meningkatkan proses penyerapan medium.

\section{Floating lag time dan total floating time}

Floating lag time (FLT) merupakan waktu yang dibutuhkan tablet untuk mengapung dalam cairan lambung. Total floating time merupakan parameter yang digunakan untuk menunjukkan seberapa lama obat atau sediaan dapat mengapung. Hasil evaluasi floating lag time dan total floating time (Tabel V). Hasil menunjukkan semakin besar persentase dari HPMC K100M dan semakin kecil presentase dari gum xanthan akan menurunkan FLT tablet. Hal ini disebabkan HPMC K100M merupakan matriks hidofilik dengan viskositas yang sangat tinggi, mempunyai ikatan partikel sangat kuat, sehingga penyerapan media memerlukan waktu yang lebih lama. Lambatnya penetrasi media ini juga memperlampat proses reaksi antara komponen effervescent di dalam tablet sehingga gas $\mathrm{CO}_{2}$ menjadi lama terbentuk dan tablet lebih lama mengapung.

\section{Penetapan kadar}

Penetapan kadar berkaitan dengan homogenitas dari bahan aktif dalam tablet sama seperti keragaman bobot. Menurut USP, rentang kadar untuk tablet floating berada pada rentang $85-115 \%$ dengan nilai SD kurang dari 6\%. Menurut hasil yang didapatkan (Tabel V), seluruh run tidak ada satupun yang melebihi syarat tersebut sehingga disimpulkan bahwa tablet yang dihasilkan seluruhnya memiliki kadar yang baik. Kadar yang didapatkan dari seluruh run berada pada rentang 91,72 98,38\%.

\section{Disolusi}

Uji disolusi menggambarkan kemampuan suatu obat dapat terlarut dalam medium tertentu selama interval waktu yang diharapkan sehingga akan menunjukkan kemampuan obat tersebut terdisolusi dalam cairan tubuh. Parameter disolusi sediaan tablet floating famotidin yang merupakan tablet sustained release adalah $\mathrm{L}_{120}, \mathrm{~L}_{240}$, dan $\mathrm{L}_{480}$. Nilai $\mathrm{L}$ adalah persentase tablet terdisolusi pada waktu yang ditentukan. Persyaratan persentase pelepasan obat pada menit ke-120 adalah $20-50 \%$, menit ke-240 adalah $45-75 \%$, dan menit ke-480 adalah lebih dari 75\% (Akbar dkk., 2012)
Hasil uji disolusi tablet floating famotidin (Tabel V) dan profil disolusi (Gambar 2). L120 dari seluruh run memenuhi persyaratan berada pada rentang 20 - 50\%. Begitu pula dengan $\mathrm{L}_{240}$ seluruh run memenuhi persyaratan berada pada rentang 45 - 75\%. Namun untuk L480 hanya run 2,6 , dan 7 yang memenuhi persyaratan $L_{480}$ yang baik yaitu lebih dari 75\%. Hal ini menunjukkan penambahan HPMC K100M dan gum xanthan meningkatkan persentase obat terdisolusi, namun kombinasi keduanya memiliki interaksi yang dapat menurunkan persentase obat terdisolusi dengan mekanisme pembentukan crosslinking yang menahan obat dan membuatnya terlepas secara perlahan.

\section{Formula Optimum Tablet Floating Famotidin} Penentuan formula optimum floating tablet famotidin dilakukan menggunakan software Design Expert ${ }^{\circledR} 10$ dengan metode simplex lattice design. Respon dengan model signifikan digunakan sebagai kriteria pemilihan formula optimum. Respon yang digunakan adalah parameter kecepatan alir granul, kecepatan penyerapan granul, kerapuhan, swelling index, floating lag time, dan $\mathrm{L}_{480}$. Formula optimum ditentukan dengan penentuan goal berupa in range, minimize, dan maximize untuk setiap respon yang digunakan. Bobot kepentingan setiap parameter menunjukkan prioritas dari masing-masing parameter dalam menentukan formula optimum. Parameter, goal, dan bobot kepentingan untuk menentukan (Tabel VI).

Formula optimum didapatkan dengan program adalah formula dengan nilai desirability tertinggi. Desirability menggambarkan adanya kedekatan hasil uji dengan nilai yang diharapkan, semakin besar nilainya dengan 1 maka semakin baik. Hasil perhitungan didapatkan formula optimum dengan kombinasi HPMC 30\% b/b dan gum xanthan $5 \% \mathrm{~b} / \mathrm{b}$ dengan desirability 0,807 .

\section{Evaluasi Formula Optimum}

Hasil pengujian parameter sifat fisik kemudian dibandingkan dengan nilai prediksi, kemudian dihitung nilai signifikansinya menggunakan metode one sample t-test dengan taraf kepercayaan 95\%. Tabel VII menunjukkan perbandingan antara hasil percobaan dengan respon prediksi.

Hasil menunjukkan bahwa seluruh $p$ value atau nilai signifikansi dari respon melebihi 
Tabel VI. Parameter, Goal, dan Bobot Kepentingan dalam Penentuan Formula Optimum Tablet Famotidin

\begin{tabular}{ccc}
\hline Parameter & Goal & Bobot kepentingan \\
\hline Kecepatan alir & Maximize & ++ \\
Kecepatan penyerapan & Maximize & + \\
Kerapuhan & Minimize & ++ \\
Swelling index & Maximize & +++ \\
Floating lag time & Minimize & ++++ \\
L480 & Target & +++++ \\
\hline
\end{tabular}

Tabel VII. Perbandingan Hasil Percobaan dengan Respon Prediksi Formula Optimum

\begin{tabular}{|c|c|c|c|c|}
\hline Respon & Hasil Percobaan & Prediksi & p-value & Keterangan \\
\hline Kecepatan alir (g/detik) & 25,03 & 25,42 & 0,716 & $\begin{array}{l}\text { Tidak berbeda } \\
\text { signifikan }\end{array}$ \\
\hline $\begin{array}{c}\text { Kecepatan penyerapan } \\
\text { ( } \mu \mathrm{g} / \text { menit })\end{array}$ & 8,18 & 8,20 & 0,808 & $\begin{array}{l}\text { Tidak berbeda } \\
\text { signifikan }\end{array}$ \\
\hline Kekerasan (kg) & 9,97 & 10,22 & 0,279 & $\begin{array}{l}\text { Tidak berbeda } \\
\text { signifikan }\end{array}$ \\
\hline Kerapuhan (\%) & 0,37 & 0,36 & 0,098 & $\begin{array}{l}\text { Tidak berbeda } \\
\text { signifikan }\end{array}$ \\
\hline Swelling index (\%) & 266,8 & 265,8 & 0,072 & $\begin{array}{l}\text { Tidak berbeda } \\
\text { signifikan }\end{array}$ \\
\hline Floating lag time (detik) & 52,08 & 54,10 & 0,226 & $\begin{array}{c}\text { Tidak berbeda } \\
\text { signifikan }\end{array}$ \\
\hline $\mathrm{L}_{120}(\%)$ & 33,57 & 32,94 & 0,126 & $\begin{array}{l}\text { Tidak berbeda } \\
\text { signifikan }\end{array}$ \\
\hline $\mathrm{L}_{240}(\%)$ & 48,36 & 49,28 & 0,527 & $\begin{array}{l}\text { Tidak berbeda } \\
\text { signifikan }\end{array}$ \\
\hline $\mathrm{L}_{480}(\%)$ & 75,36 & 75,05 & 0,554 & $\begin{array}{l}\text { Tidak berbeda } \\
\text { signifikan }\end{array}$ \\
\hline NP $(\%)$ & 1,69 & 1,76 & 0,277 & $\begin{array}{l}\text { Tidak berbeda } \\
\text { signifikan }\end{array}$ \\
\hline
\end{tabular}

0,05 yang bermakna antara hasil percobaan dengan nilai prediksi tidak berbeda signifikan sehingga metode yang digunakan dapat dinyatakan valid dan dipercaya untuk menyusun formula tablet floating yang optimum.

\section{KESIMPULAN}

Peningkatan

HPMC

K100M meningkatkan daya serap granul, kekerasan tablet, dan swelling index secara signifikan. Peningkatan gum xanthan meningkatkan kecepatan alir granul, kerapuhan tablet, dan floating lag time secara signifikan. Kombinasi keduanya menurunkan persentase obat terdisolusi secara signifikan. Formula optimum tablet floating famotidin merupakan formula dengan kombinasi HPMC K100M sebesar 30\% dan gum xanthan sebesar $5 \%$.

\section{DAFTAR PUSTAKA}

Ajay Kumar, Ashni Verma, Geetika Sharma, Rupinder Saini, Shivani Sharma, Sukhdev Singh, Upendra K Jain, Mandeep Sharma., 2013, Formulation and Characterization of Effervescent Floating Matrix Tablets of Famotidine Hydrochloride, Asian Journal of Biomedical and Pharmaceutical Sciences 3 (25), 43-47.

Akbar, H.F., Sugiyartono, dan Dwi Setiawan, 2012, Pengaruh Penambahan Manitol Terhadap Pelepasan Ranitidin $\mathrm{HCl}$ dari 
Optimasi Formula Tablet Floating Famotidin Menggunakan Kombinasi Matriks Gum Xanthan

Tablet Floating dengan HPMC K100M Sebagai Matriks, PharmaScientia 1(1), 30-45.

AOAC International, 2012, Appendix F: Guidelines for Standard Method Performance Requirements, dalam Latimer, G. W., Official Methods of Analysis of AOAC International, 1-17, Association of Official Analytical Chemists International, Rockville.

Bomma R, 2009. Development and Evaluation of Gastroretentive Norfloxa-cin Floating Tablets, Acta Pharm 59(2), 211-221.

Cahyo, Hadi, 2012, Optimasi Kombinasi Hidroksipropil MetilSelulosa Sebagai Matriks dan Avicel PH 101 Sebagai Filler Binder Untuk Formula Tablet Kapropril Lepas Lambat Sistem Floating, Fakultas Farmasi Universitas Muhammadiyah Surakarta, Surakarta.

Departemen Kesehatan, 2014, Farmakope Indonesia Edisi V, 164-165, 413-415, 805806, 1526-1528, 1605-1607, Departemen Kesehatan RI., Jakarta.

Hadisoewigno, L. dan Fudholi, A., 2007, Studi Pelepasan In Vitro Ibuprofen Dari Matriks Gum xanthan yang Dikombinasikan Dengan Suatu Crosslinking Agent, Majalah Farmasi Indonesia 18 (3), 133-140.

Iskandarsyah, Sutrio, Hayati, D., Pengaruh Kombinasi Hidroksipropil Metilselulosa-
Gum xanthan Sebagai Matriks Pada Profil Pelepasan Tablet Teofilin Lepas Terkendali, Majalah Ilmu Kefarmasian 7 (3), 58-70.

Mariyana, K.A., Arisanti, C.I.S., Setyawan, E.I., 2012, Pengaruh Konsentrasi Amilum Jagung Pregelatinasi Sebagai Bahan Penghancur Terhadap Sifat Fisik Tablet Vitamin E, Jurnal Farmasi Udayana 1(1), 39-49.

Sagita, Erni, Effionora Anwar, Silvia Surini, 2011, Pembuatan Sediaan Tablet Mengapung Famotidin Menggunakan Kompleks Polielektrolit Kitosan-Pektin sebagai Bahan Matriks, Majalah Ilmu Kefarmasian 8 (1), 38-48.

Siswanto, A. dan Sulihtyowati, S. 2006, Optimasi Formulasi Sediaan Tablet Lepas Lambat Teofilin dengan Bahan Matrik HPMC, Na CMC dan Gum xanthan, Majalah Farmasi Indonesia 17(3), 143-148.

Suwaldi dan Faizah, Z., 1994, Pelepasan Parasetamol Dari Sediaan Lepas Lambat Dengan Matriks Hidroksipropil Metilselulosa, Majalah Farmasi Indonesia 5(4), 168-174.

Swarbrick, 1992, Encyclopedia of Pharmaceutical Technology, Volume V, 189, Marcel Dekker Inc., New York.

The United State Pharmacopeial Convention, 2005, The United States Pharmacopeia (USP), 28 ${ }^{\text {th }}$ Edition, 2928, United States. 